\title{
A meta-analysis comparing transaxillary and transfemoral transcatheter aortic valve replacement
}

\author{
Yong Zhan, Siavash Saadat, Avneet Soin, Masashi Kawabori, Frederick Y. Chen \\ Division of Cardiac Surgery, Tufts Medical Center, Tufts University School of Medicine, Boston, MA, USA \\ Contributions: (I) Conception and design: Y Zhan, M Kawabori; (II) Administrative support: F Chen; (III) Provision of study materials or patients: \\ None; (IV) Collection and assembly of data: Y Zhan, S Saadat, A Soin; (V) Data analysis and interpretation: Y Zhan, S Saadat, A Soin; (VI) \\ Manuscript writing: All authors; (VII) Final approval of manuscript: All authors. \\ Correspondence to: Yong Zhan, MD. Division of Cardiac Surgery, Tufts Medical Center, 800 Washington Street, \#266, Boston, MA 02111, USA. \\ Email: yzhan@tuftsmedicalcenter.org.
}

\begin{abstract}
Background: While transfemoral (TF) approach is considered as the default access for transcatheter aortic valve replacement (TAVR), the alternative access route of choice remains to be elucidated. Transaxillary (TAx) approach has shown promise as an excellent option. We performed a meta-analysis of the studies comparing the TF and TAx approaches using one type of self-expandable transcatheter valve to avoid device-related bias.

Methods: We searched PubMed/MEDLINE, EMBASE, and the Cochrane Library from inception to December 2018 to identify articles comparing TAx-TAVR and TF-TAVR. The studies included in this metaanalysis contain data related to the use of the CoreValve device. Patients' baseline characteristics, procedural outcomes, and clinical outcomes were extracted from the articles and pooled for analysis.

Results: The meta-analysis included five studies comprising 1,414 patients in the TF group and 489 patients in the TAx group. The average EuroScores of the TF and TAx groups were $20.04 \pm 13.89$ and $22.73 \pm 14.73$, respectively. The TAx group has higher rates of major comorbidities. No difference was found between the two groups with regard to vascular complications ( $\mathrm{P}=0.71$; OR 1.08; 95\% CI, 0.71-1.65), aortic regurgitation ( $\mathrm{P}=0.90$; OR 1.03; 95\% CI, 0.71-1.49), and permanent pacemaker (PPM) implantation $(\mathrm{P}=0.42$; OR 1.12; 95\% CI, 0.86-1.46). The TAx group has a lower incidence of acute kidney injury (AKI) $(\mathrm{P}=0.05$; OR 1.63; 95\% CI, 1.01-2.62). No difference was observed in 30-day mortality (P=0.32; OR 1.30; 95\% CI, $0.78-2.17$ ) or 1 -year mortality ( $\mathrm{P}=0.21$; OR 0.76 ; $95 \%$ CI, 0.50-1.16).
\end{abstract}

Conclusions: TAx-TAVR is associated with overall comparable outcomes to TF TAVR in high-risk patient cohorts, despite higher incidences of major comorbidities in the TAx-TAVR patient population. The rate of AKI appears to be lower after TAx-TAVR.

Keywords: Transcatheter aortic valve replacement (TAVR); transaxillary (TAx); transfemoral (TF)

Submitted Aug 07, 2019. Accepted for publication Nov 19, 2019.

doi: $10.21037 /$ jtd.2019.12.07

View this article at: http://dx.doi.org/10.21037/jtd.2019.12.07

\section{Introduction}

Transcatheter aortic valve replacement (TAVR) has become a valid strategy for patients with severe aortic valve stenosis $(1,2)$. The transfemoral (TF) approach is considered as the access route of choice for TAVR as it is associated with superb outcomes (3). When suboptimal iliofemoral vessels preclude a TF approach, other access routes are sought for alternatives, among which transaxillary (TAx) approach has shown promise as a preferred option (4-6). However, the safety and efficacy of TAx-TAVR remain to be elucidated.

A marked reduction in the use of alternative access has been achieved in recent years with improvement in the delivery devices. Despite the advances, about $10-15 \%$ 
of TAVR cases are currently performed using alternative access, and the choice of alternative access route remains controversial (7). Compared to transaortic or transapical access route, TAx-TAVR is less invasive and associated with improved recovery (8-10). As a major advantage, TAxTAVR involves no thoracotomy/sternotomy; thus, it could be done either percutaneously or with a surgical cut-down with local anesthesia and under sedation (11). Therefore, expedited recovery can be expected.

The Choice Trial has demonstrated that the outcomes of TAVR are device-specific (12). The variable outcomes of self-expandable valves $v s$. balloon-expandable valves need to be taken into account when a meta-analysis is conducted, as valve type will have an influence on the results. The selfexpandable CoreValve (Medtronic, Minneapolis, MN, USA) is the most frequently applied transcatheter heart valve (THV) for TAx-TAVR (8-10). While the outcomes of TAVR are device-specific, the majority of previous studies contained unstratified data with regard to devices used $(13,14)$. We performed a meta-analysis of the studies comparing the TF-TAVR and TAx-TAVR using the CoreValve device to avoid device-related bias.

\section{Methods}

\section{Literature search strategy}

A systemic search of the PubMed/MEDLINE, EMBASE, and the Cochrane Library from the inception to December 2018 was conducted to identify full peer review articles in English comparing TAx-TAVR and TF-TAVR. Search terms included "transcatheter aortic valve transaxillary", "transcatheter aortic valve transfemoral transaxillary", "transcatheter aortic valve transfemoral subclavian", "transcatheter aortic valve trans-femoral trans-subclavian", "transcatheter aortic valve transfemoral subclavian", and "transcatheter aortic valve transfemoral axillary". We used the terminology of axillary access as the substitute of subclavian access for TAVR, as trans-subclavian approach is considered a misnomer unless a supraclavicular cut-down is involved, and trans-subclavian and transaxillary approach are interchangeable in the literature $(3,7)$.

\section{Eligibility criteria}

Studies were considered eligible if they are (I) randomized controlled trials or observational studies, (II) at least
10 patients are included in the studies, (III) patient demographics are reported, (IV) sufficient data of outcomes for both approaches, (V) studies include data related to the use of CoreValves or the data on CoreValves are separately reported. Studies were excluded if there is insufficient or inadequate data for analysis, if the study is a case report or review, and if there is duplicate or overlapping data including the studies from the same institutions and contributed by the authors who participated in other studies selected for this meta-analysis. The literature search, systemic review, and meta-analysis were conducted following published guidance $(15,16)$. Discrepancies between reviewers were resolved by discussion until a consensus was reached. Study Quality Assessment was performed following the criteria recommended by the University of Oxford Centre for Evidence Based Medicine $(15,17)$.

\section{Statistical analysis}

Continuous variables are presented as means \pm standard deviation (SD), and categoric variables are presented as percentages. Median is considered as mean, and SD is calculated by dividing the interquartile range by 1.35 . The Cochrane Collaboration Review Manager 5.3 software was used for meta-analysis. For forest plots, the odds ratio (OR) was used as a summary statistic, and $95 \%$ confidence intervals based on Mantel-Haenszel $\chi^{2}$ were estimated to compare outcomes. Both fixed- and random-effect models were tested. The results using the random-effects model were presented. The heterogeneity of outcomes between the studies was determined using the $\chi^{2}$ test. $\mathrm{I}^{2}$ statistic and degree of freedom (df) were calculated to estimate the variation across studies. Statistical significance for hypothesis testing was set at the 0.05 level. Publication bias was analyzed by funnel plots.

\section{Results}

\section{Literature search}

Five studies met the inclusion criteria for meta-analysis (Figure 1), and an overview of these studies is summarized in Table 1. All five studies contain data comparing TF-TAVR and TAx-TAVR with the CoreValve device, although in two studies the authors also discuss other valve types such as the Edwards SAPIEN valve $(9,18)$. For the purposes of this 


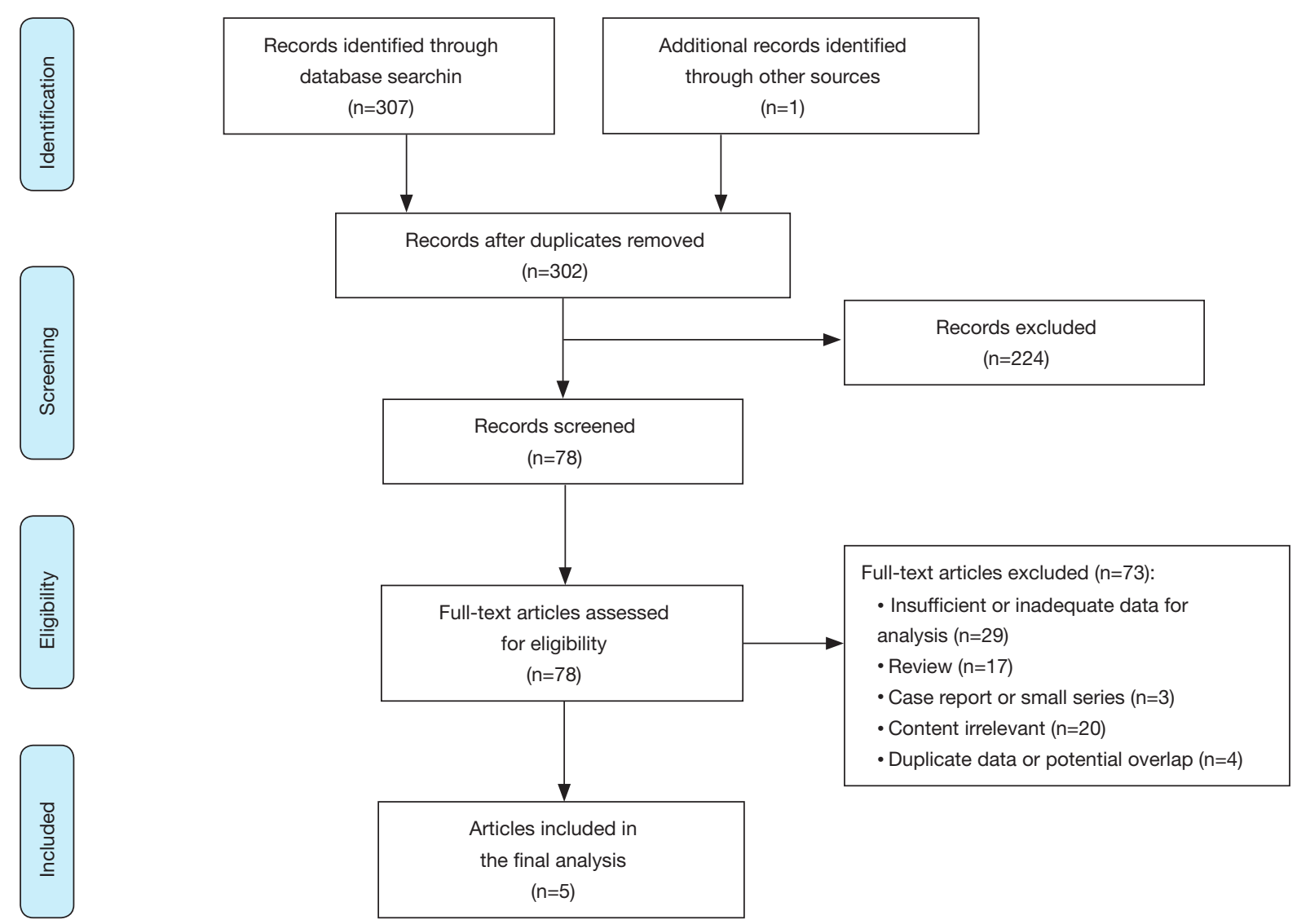

Figure 1 Summary of the systematic search and identification of eligible studies (PRISMA flow diagram).

study, only the demographic and outcome data pertinent to the use of CoreValve devices were extracted for analysis. Of the included studies, no randomized controlled trials were identified. Four of the five studies were from multicenter prospective data registries $(4,6,9,18)$. Two studies performed propensity-score matching $(4,6)$. A quality assessment of each study was performed (Table 2). These studies are considered as high quality and acceptable for meta-analysis, albeit the TAx group has fewer patients in the studies without propensity-score matching $(5,9,18)$.

\section{Patient demographics}

Overall the five studies comprising this meta-analysis involve a total of 1,903 patients, with 1,414 patients in the TF group and 489 patients in the TAx group. Patient characteristics are summarized in Table 3. Comparison of the study demographic data showed that the pooled mean age and EuroScores for the TAx group were similar to the TF group (Table 4). Compared to the TF group, the patient population of the TAx group was associated with significantly higher of the following characteristics: male gender $(63.0 \%$ vs. $52.6 \% ; \mathrm{P}=0.005)$, peripheral vascular disease $(65.2 \%$ vs. $24.0 \% ; \mathrm{P}=0.01)$, coronary artery disease (66.7\% vs. $51.1 \% ; \mathrm{P}=0.05)$, and ejection fraction $<50 \%$ (47.0\% vs. $37.2 \% ; \mathrm{P}=0.03)$. There was no statistical significance found between the TAx and TF groups for diabetes mellitus $(36.0 \%$ vs. $27.5 \% ; \mathrm{P}=0.95)$, chronic pulmonary disease $(50.6 \%$ vs. $31.8 \% ; \mathrm{P}=0.90)$, creatinine (Cr) $>2 \mathrm{mg} / \mathrm{dL}(8.5 \%$ vs. $7.0 \% ; \mathrm{P}=0.59)$, cerebral vascular disease $(13.3 \%$ vs. $12.6 \% ; \mathrm{P}=0.11)$, prior cardiac surgery ( $31.9 \%$ vs. $27.8 \% ; \mathrm{P}=0.26$ ), or New York Heart Association class III/IV (82.8\% vs. $86.9 \%$; $\mathrm{P}=0.69)$.

\section{Meta-analysis of outcomes}

\section{0-day mortality}

The incidence of 30-day mortality was provided by all five 
Table 1 Summary of studies included in the meta-analysis

\begin{tabular}{|c|c|c|c|c|c|c|c|}
\hline Study & $\begin{array}{l}\text { Year } \\
\text { published }\end{array}$ & Country & Study period & $\mathrm{TF}(\mathrm{n})$ & TAx (n) & Type of THV & Summary \\
\hline Blackman (9) & 2014 & $\begin{array}{l}\text { United } \\
\text { Kingdom }\end{array}$ & 2007-2010 & 704 & 94 & $\begin{array}{l}\text { CoreValve (Sapien valve } \\
\text { data not extracted) }\end{array}$ & $\begin{array}{l}\text { Retrospective study of } \\
\text { the prospective UK TAVI } \\
\text { Registry data }\end{array}$ \\
\hline Eltchaninoff (18) & 2010 & France & 2009 & 66 & 12 & $\begin{array}{l}\text { CoreValve (Sapien valve } \\
\text { data not extracted) }\end{array}$ & $\begin{array}{l}\text { Retrospective study of } \\
\text { prospective multicenter } \\
\text { registry data }\end{array}$ \\
\hline Gleason (4) & 2018 & $\begin{array}{l}\text { United } \\
\text { States }\end{array}$ & 2010-2014 & 202 & 202 & CoreValve & $\begin{array}{l}\text { Propensity-matched } \\
\text { analysis of the CoreValve } \\
\text { US Pivotal Trial and } \\
\text { Continued Access Study }\end{array}$ \\
\hline Muensterer (5) & 2013 & Germany & 2007-2011 & 301 & 40 & CoreValve & $\begin{array}{l}\text { Retrospective single-center } \\
\text { study }\end{array}$ \\
\hline
\end{tabular}

TAx, transaxillary; TF, transfemoral; THV, transcatheter heart valve.

Table 2 Quality assessment of studies

\begin{tabular}{|c|c|c|c|c|c|}
\hline Assessment & Blackman (9) & Eltchaninoff (18) & Gleason (4) & Muensterer (5) & Petronio (6) \\
\hline $\begin{array}{l}\text { Clear definition of outcomes and } \\
\text { outcome assessment? }\end{array}$ & Yes & Yes & Yes & Yes & Yes \\
\hline $\begin{array}{l}\text { Independent assessment of outcome } \\
\text { parameters? }\end{array}$ & Yes & Yes & Yes & Unclear & Yes \\
\hline No selective loss during follow-up? & Yes & Yes & Unclear & Unclear & Yes \\
\hline $\begin{array}{l}\text { Important confounders and prognostic } \\
\text { factors identified? }\end{array}$ & Yes & Yes & Yes & Yes & Yes \\
\hline
\end{tabular}

studies (Table 5). The pooled results showed no significant difference between the two groups [TF vs. TAx; $6.5 \%$ vs. $5.1 \%$; OR $1.30 ; 95 \% \mathrm{CI}, 0.78-2.17 ; \mathrm{P}=0.32]$ with no heterogeneity $\left(\mathrm{I}^{2}=0 \%\right)$ (Figure 2).

\section{1-year mortality}

Three studies reported 1-year mortality/survival $(4,5,9)$. The TAx cohorts of these three studies are associated with higher EuroScores $(22.3 \pm 14.9$ vs. $19.4 \pm 13.9$; $\mathrm{P}=0.04)$. Although the 1 -year mortality rate of the TAx group is numerically higher $(25.0 \%$ vs. $19.9 \%)$ compared to the $\mathrm{TF}$ group, we found no statistical difference (OR 0.76; 95\% CI, 0.50-1.16; $\mathrm{P}=0.21)$ with low heterogeneity $\left(\mathrm{I}^{2}=46 \%\right)$
(Figure 2).

\section{Acute kidney injury (AKI)}

The incidence of AKI was provided by three studies (4-6). The pooled results showed a significant difference between the two groups using the fixed-effect model (11.6\% vs. $7.8 \%$; OR 1.64; 95\% CI, 1.01-2.64; $\mathrm{P}=0.04$ ) with no heterogeneity $\left(\mathrm{I}^{2}=0 \%\right)$, although in the random-effect model the difference was less significant (OR 1.63; 95\% CI, 1.01-2.62; $\mathrm{P}=0.05$ ) (Figure 2).

\section{Other outcomes}

The pooled results of all five studies did not show any 


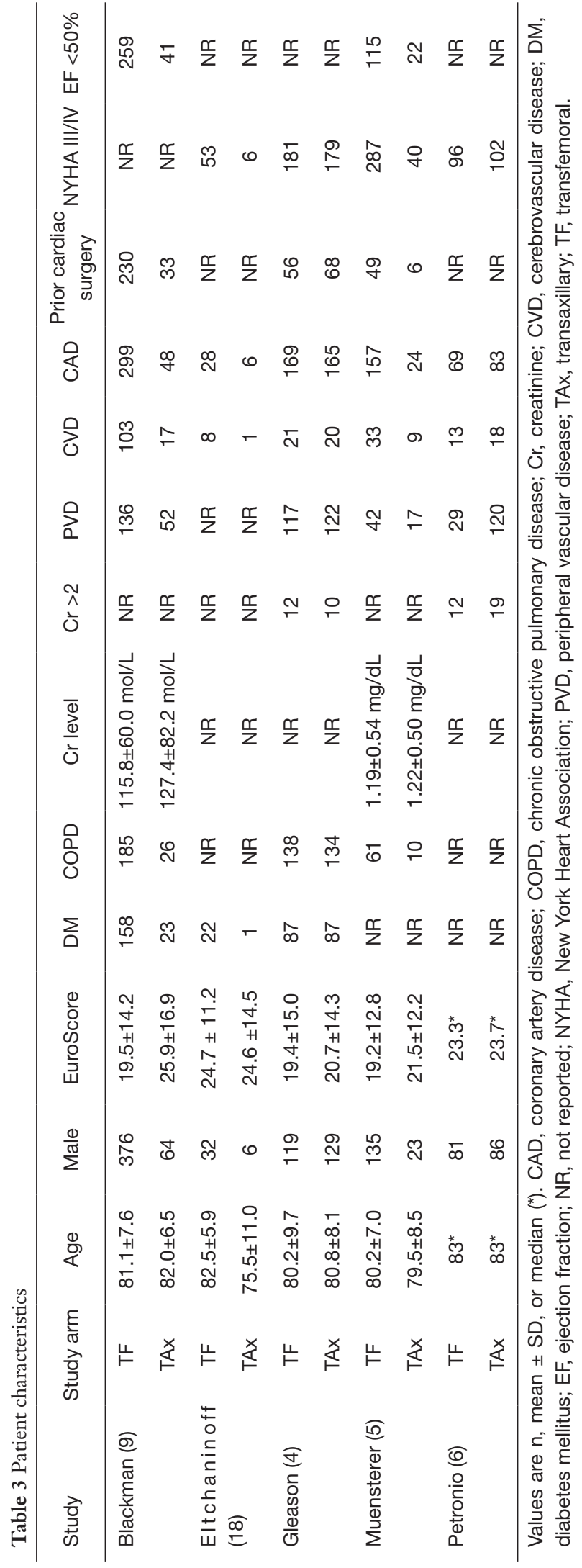

significant difference with no heterogeneity $\left(\mathrm{I}^{2}=0 \%\right)$ between the two groups (TF vs. TAx) with regard to the rates of permanent pacemaker (PPM) implant $(24.5 \%$ vs. $22.5 \%$; OR 1.12; 95\% CI, 0.86-1.46; $\mathrm{P}=0.42$ ), vascular complications $(7.8 \%$ vs. $8.2 \%$; OR 1.08 ; $95 \%$ CI, $0.71-$ 1.65; $\mathrm{P}=0.71)$, and stroke (3.3\% vs. $3.8 \%$; OR $0.84 ; 95 \%$ CI, $0.44-1.62 ; \mathrm{P}=0.60)$. The pooled results of 3 studies that reported data on life-threatening bleeding also did not reveal significant difference between the two groups (6.8\% vs. 9.1\%; OR 0.89; 95\% CI, 0.53-1.47; $\mathrm{P}=0.64$ ) with no heterogeneity (4-6). Four studies reported data on aortic regurgitation (4-6,9). The pooled results showed no difference between the TF and TAx groups (12.8\% vs. $11.8 \%$; OR $1.03 ; 95 \%$ CI, $0.71-1.49 ; \mathrm{P}=0.90)$ with no heterogeneity $\left(\mathrm{I}^{2}=0 \%\right)$ (Figure 2$)$.

\section{Meta-analysis of propensity-score matched studies}

Subgroup analysis was also performed on the two studies with propensity-score matching $(4,6)$. Demographic data are similar in the TF and TAx cohorts, including the percentages of patients with $\mathrm{Cr}>2 \mathrm{mg} / \mathrm{dL}$ preoperatively (7.0\% vs. $8.5 \%$; OR $0.83 ; 95 \% \mathrm{CI}, 0.41-1.65 ; \mathrm{P}=0.59$ ). There is no difference identified among the studied outcomes except AKI, which is higher in the TF group (12.5\% vs. 7.6\%; OR 1.74; 95\% CI, 1.04-2.92; $\mathrm{P}=0.04$ ) with no heterogeneity $\left(\mathrm{I}^{2}=0 \%\right)$. The pooled results showed no significant differences in mortality at 30-day (OR 1.11; 95\% CI, 0.59-2.11; $\mathrm{P}=0.96)$ or during the longest followup periods (OR 1.05; 95\% CI, 0.74-1.48; $\mathrm{P}=0.79)$ with no heterogeneity $\left(\mathrm{I}^{2}=0 \%\right)$ (Figure 3$)$.

\section{Discussion}

Data on the safety and efficacy of TAx-TAVR are scant. There are no randomized controlled studies comparing it to other TAVR approaches as to date. Previous meta-analysis studies comparing the TAx and TF approaches suggest that these techniques are associated with similar procedural and clinical outcomes $(13,14)$. However, these studies did not either stratify the devices or provide sufficient data. With the knowledge that the outcome of TAVR can be devicerelated, the results were suggestive but not conclusive. We performed an updated literature search and focused on the CoreValve device, as it is the predominant device used for TAx-TAVR, to have a better comparison of the two TAVR approaches.

The major findings of this meta-analysis include that 
Table 4 Comparison of patient characteristics between TF-TAVR and TAx-TAVR Cohorts

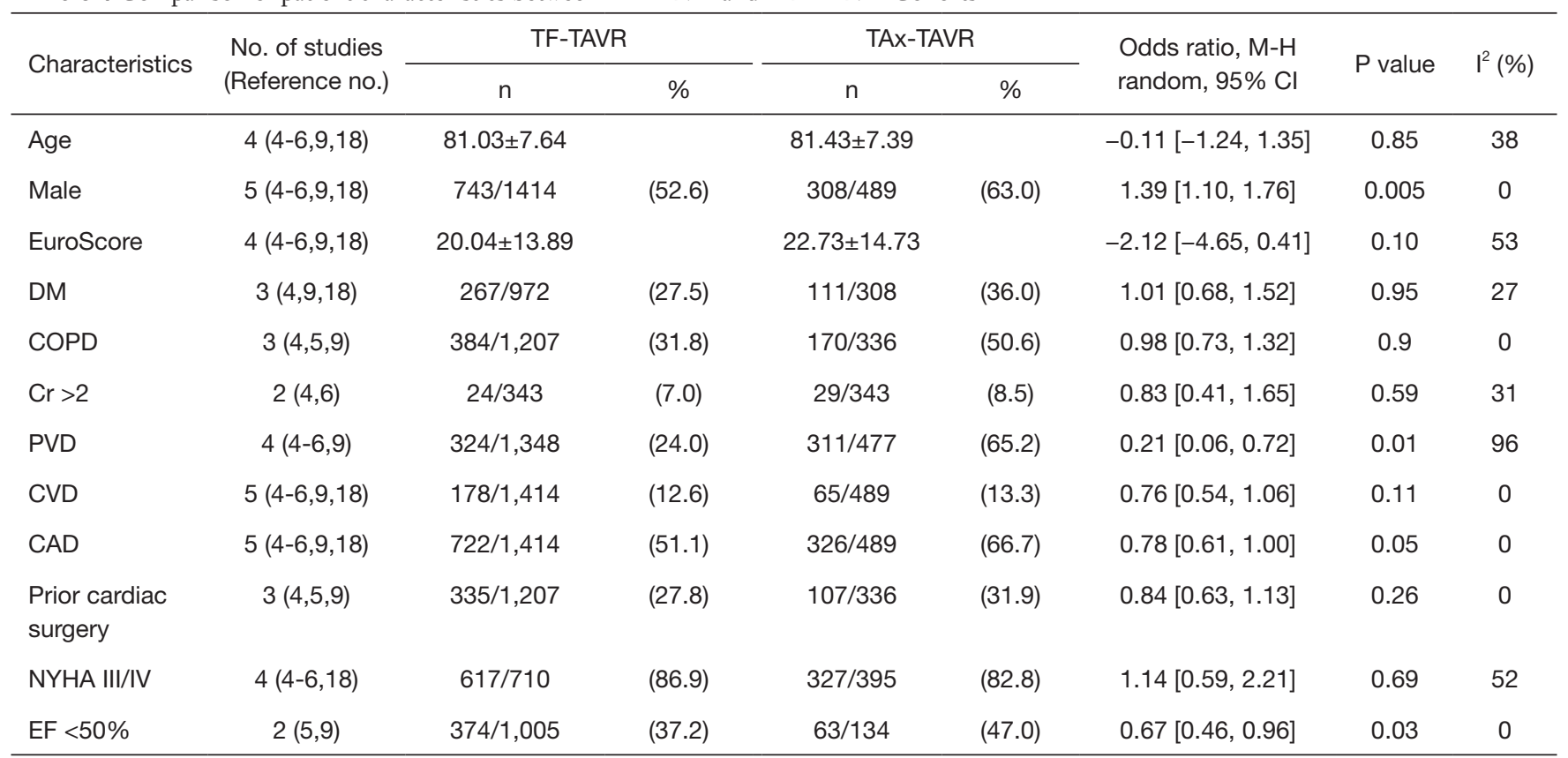

Values are proportion and ratio (in parenthesis), mean $\pm \mathrm{SD}$, or odds ratio with $95 \%$ confidence interval (in bracket). Cl, confidence interval; $\mathrm{M}-\mathrm{H}$, Mantel-Haenszel; CAD, coronary artery disease; COPD, chronic obstructive pulmonary disease; Cr, creatinine; CVD, cerebrovascular disease; DM, diabetes mellitus; EF, ejection fraction; NYHA, New York Heart Association; PVD, peripheral vascular disease; TAx, transaxillary; TF, transfemoral.

the TAx and TF approaches do not differ in most of the major outcomes. As observed in the current meta-analysis, the rate of moderate or severe $(>2+)$ aortic regurgitation was irrelevant to the approaches. This was strengthened by the finding that the PPM implant rates were also similar between the two groups, $22.5 \%$ for the pooled TAx group and $24.5 \%$ for the TF group, consistent with reports in the literature on the TF approach $(19,20)$. van der Wulp and colleagues reported their outcomes of left TAx-TAVR as the primary access site (21), and their PPM implant rate was $11 \%$, which is significantly lower compared to the rate of $28 \%$ reported in the literature on the CoreValve (19). The low rate of PPM implant is possibly related to their use of the left axillary artery, which is more coaxial with the aorta, potentially resulting in better valve positioning compared with the right axillary access route. Our data is in accordance with the meta-analysis performed by Garcia et al. (14), showing that the TAx and TF approaches had a similar incidence of PPM implant when the utility of TAVR devices was stratified. Amat-Santos (13) showed a nonsignificant lower trend of PPM requirement for the TF group, possibly due to the fact that $32.3 \%(1,254 / 3,886)$ of the devices used in the TF group were SAPIEN valves, which are known for lower PPM requirement compared to early generation CoreValve devices (19,20,22).

TAx access is associated with concerns for upper limb ischemia, which is less tolerated when such a vascular complication does occur $(23,24)$. Our meta-analysis shows no difference in the incidence of vascular complications between the TAx and TF groups. The vascular complication rate in the TF group is consistent with clinical trials where TF-TAVRs with the CoreValve device are associated with incidences of vascular complications ranging from $3 \%$ to $11 \%(25-27)$. However, the outcomes did not specify the location of the complication. Thus, it is possible that the vascular complications reported for the TAx group could involve the femoral access site as opposed to the axillary site, thereby offsetting the data. van der Wulp et al. reported major vascular complications occurred in $5 \%$ of their patients, only $1 \%$ was related to the axillary access (21). TAx-TAVR could be percutaneously accessed, potentially making it one of the favored access options for TAVR $(28,29)$, although it has been reported that about $10 \%$ of patients who underwent percutaneous TAx-TAVR 


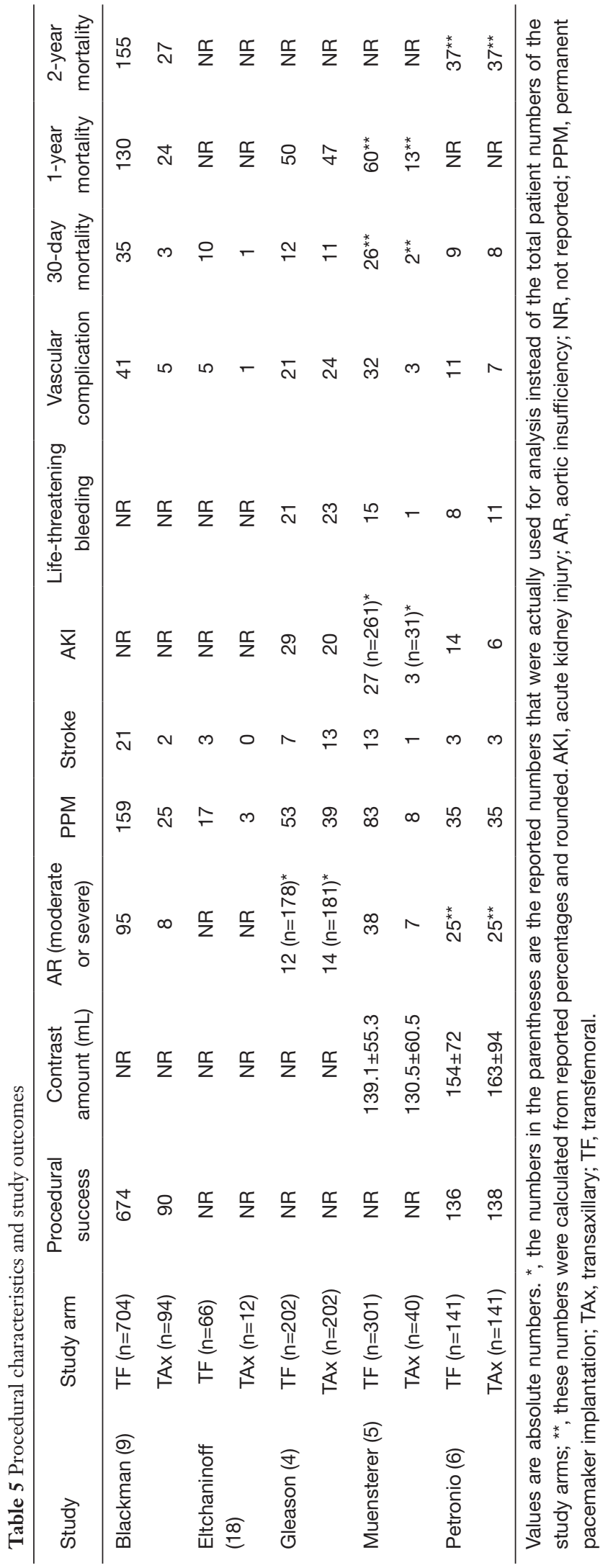

received adjunct endovascular stent placement for vascular complication in a large case series (30). In contrast, various studies on TAx-TAVR where the axillary/subclavian artery was surgically isolated have demonstrated low incidences of vascular complications in a range of $0 \%$ to $6 \%$, lower than that of TF-TAVR $(31,32)$.

Out of all the outcomes, the only difference that reaches statistical significance was the occurrence of AKI, which favored the TAx group. Although only three papers reported postoperative outcome data on AKI, it appears that their patients at risk preoperatively were matched between the TF and TAx groups as the percentage of patients with $\mathrm{Cr}$ $>2 \mathrm{mg} / \mathrm{dL}$ were similar in the studies $(4,6)$, and Muensterer et al. also reported corresponding baseline Cr levels of the TAx- and TF-TAVR patients (5). The cause of low AKI incidence with TAx-TAVR is unclear. It was hypothesized that the TAx access could be associated with a shorter route and easier device positioning, thereby shortening the fluoroscopy time and reducing the amount of contrast. The TF group appeared to have a lower AKI rate in the AmatSantos meta-analysis, although it did not reach statistical significance (13). The Garcia meta-analysis did not include AKI as an outcome (14). Although there could be selection bias between our meta-analysis, the data appears to be homogenous among the three papers that contain the AKI data. This result was further confirmed by our subgroup analysis of the two propensity-matched studies (Figure 3). Petronio and colleagues also observed that the rate of acute kidney injury/stage 3 was significantly lower in the subclavian group $(4.3 \%$ vs. $9.9 \%, \mathrm{P}=0.02)$ despite a higher percentage of subclavian access patients with serum $\mathrm{Cr}>2 \mathrm{mg} / \mathrm{dL}$ (13.5\% vs. $8.5 \%, \mathrm{P}=0.24)$. They postulated that it was possibly related to a higher amount of contrast medium was administered to the patients in the TF group due to the need for angiographic control of the iliofemoral arteries (6). However, their hypothesis was not confirmed by the data reported in two other studies included in our metaanalysis (Table 5), which revealed that the intraprocedural contrast doses were comparable between the TAx and TF groups $(5,18)$.

Our data showed no significant difference in the 30-day mortality rates between the TF and TAx groups. This is consistent with the previous meta-analysis $(13,14)$, suggesting the comparable invasiveness of TAx-TAVR and TF-TAVR. van der Wulp et al. demonstrated that the 30-day mortality and 1-year mortality observed with left TAx-TAVR as the primary access site were $5 \%$ and $19 \%$, which were similar to the pooled results previously 
Acute kidney injury

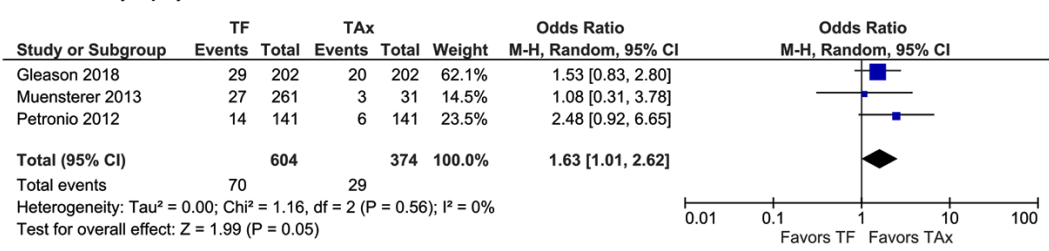

Aortic regurgitation

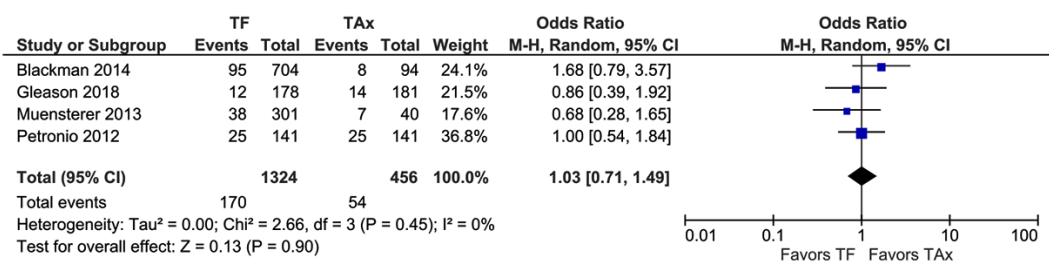

Permanent pacemaker implantation

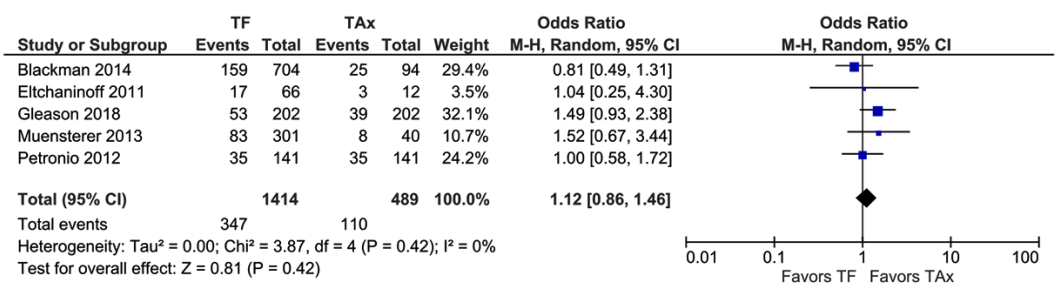

Vascular complications

\begin{tabular}{|c|c|c|c|c|c|c|c|c|c|}
\hline Study or Subgroup & $\begin{array}{r}\mathrm{TF} \\
\text { Events }\end{array}$ & Total & $\begin{array}{r}\text { TAx } \\
\text { Events }\end{array}$ & & Weight & $\begin{array}{l}\text { Odds Ratio } \\
\text { M-H, Random, } 95 \% \mathrm{Cl}\end{array}$ & & $\begin{array}{l}\text { Odds Ratio } \\
\text { M-H, Random, } 95 \% \mathrm{Cl}\end{array}$ & \\
\hline Blackman 2014 & 41 & 704 & 5 & 94 & $19.6 \%$ & $1.10[0.42,2.86]$ & & & \\
\hline Eltchaninoff 2011 & 5 & 66 & 1 & 12 & $3.6 \%$ & $0.90[0.10,8.48]$ & & & \\
\hline Gleason 2018 & 21 & 202 & 24 & 202 & $46.3 \%$ & $0.86[0.46,1.60]$ & & - & \\
\hline Muensterer 2013 & 32 & 301 & 3 & 40 & $11.8 \%$ & $1.47[0.43,5.03]$ & & & \\
\hline Petronio 2012 & 11 & 141 & 7 & 141 & $18.7 \%$ & $1.62[0.61,4.31]$ & & - & \\
\hline Total $(95 \% \mathrm{Cl})$ & & 1414 & & 489 & $100.0 \%$ & $1.08[0.71,1.65]$ & & & \\
\hline Total events & 110 & & 40 & & & & & & \\
\hline $\begin{array}{l}\text { Heterogeneity: } \operatorname{Tau}^{2}= \\
\text { Test for overall effect: }\end{array}$ & $\begin{array}{l}.00 ; \mathrm{Ch}^{2} \\
=0.37(\end{array}$ & $\begin{array}{l}=1.44, \\
=0.71\end{array}$ & & $=0.84)$ & $; 1^{2}=0 \%$ & & 0.01 & $0.1{ }^{1}{ }^{1} 10$ & 100 \\
\hline
\end{tabular}

30-day mortality

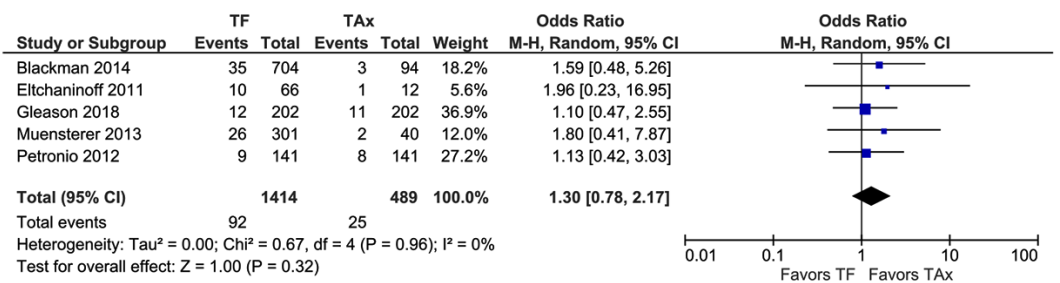

1 -year mortality

\begin{tabular}{|c|c|c|c|c|c|c|c|c|c|}
\hline Study or Subgroup & $\begin{array}{r}\text { TF } \\
\text { Events }\end{array}$ & Total & $\begin{array}{l}\text { TAx } \\
\text { Events }\end{array}$ & & Weight & $\begin{array}{l}\text { Odds Ratio } \\
\text { M-H, Random, } 95 \% \mathrm{Cl}\end{array}$ & & $\begin{array}{c}\text { Odds Ratio } \\
\text { M-H, Random, } 95 \% \text { Cl }\end{array}$ & \\
\hline Blackman 2014 & 130 & 704 & 24 & 94 & $36.4 \%$ & $0.66[0.40,1.09]$ & & $\rightarrow$ & \\
\hline Gleason 2018 & 50 & 202 & 47 & 202 & $39.8 \%$ & $1.08[0.69,1.71]$ & & & \\
\hline Muensterer 2013 & 60 & 301 & 13 & 40 & $23.8 \%$ & $0.52[0.25,1.06]$ & & & \\
\hline Total $(95 \% \mathrm{Cl})$ & & 1207 & & 336 & $100.0 \%$ & $0.76[0.50,1.16]$ & & & \\
\hline Total events & 240 & & 84 & & & & & & \\
\hline $\begin{array}{l}\text { Heterogeneity: } \text { Tau }^{2}= \\
\text { Test for overall effect: }\end{array}$ & $\begin{array}{l}0.07 ; \mathrm{Ch}^{2} \\
\mathrm{z}=1.26(\mathrm{~F}\end{array}$ & $\begin{array}{l}=3.68, \\
P=0.21\end{array}$ & & & $j^{\prime} I^{2}=4$ & & 0.01 & 0.1 & $100^{\prime}$ \\
\hline
\end{tabular}

Figure 2 Forest plots for the comparison of outcomes of patients undergoing transaxillary and transfemoral TAVR. TAx, transaxillary; TF, transfemoral. 
30-day mortality

\begin{tabular}{|c|c|c|c|c|c|c|c|c|c|}
\hline Study or Subgroup & $\begin{array}{r}\text { TF } \\
\text { Events } \\
\end{array}$ & Total & $\begin{array}{r}\text { TAx } \\
\text { Events }\end{array}$ & Total & Weight & $\begin{array}{c}\text { Odds Ratio } \\
\text { M-H, Random, } 95 \% \mathrm{Cl}\end{array}$ & & $\begin{array}{c}\text { Odds Ratio } \\
\text { M-H, Random, } 95 \% \mathrm{Cl}\end{array}$ & \\
\hline Gleason 2018 & 12 & 202 & 11 & 202 & $57.6 \%$ & $1.10[0.47,2.55]$ & & & \\
\hline Petronio 2012 & 9 & 141 & 8 & 141 & $42.4 \%$ & $1.13[0.42,3.03]$ & & & \\
\hline Total $(95 \% \mathrm{Cl})$ & & 343 & & 343 & $100.0 \%$ & $1.11[0.59,2.11]$ & & & \\
\hline Total events & 21 & & 19 & & & & & & \\
\hline \multicolumn{7}{|c|}{$\begin{array}{l}\text { Heterogeneity: } \mathrm{Tau}^{2}=0.00 ; \mathrm{Chi}^{2}=0.00, \mathrm{df}=1(\mathrm{P}=0.96) ; \mathrm{I}^{2}=0 \% \\
\text { Test for overall effect: } Z=0.33(P=0.74)\end{array}$} & 0.01 & $\begin{array}{l}0.1 \\
\text { Favors TF }\end{array}{ }^{1}$ Favors TAx & 100 \\
\hline
\end{tabular}

\section{1-2 year mortality}

\begin{tabular}{|c|c|c|c|c|c|c|c|c|c|}
\hline Study or Subgroup & $\begin{array}{r}\text { TF } \\
\text { Events } \\
\end{array}$ & Total & $\begin{array}{l}\text { TAx } \\
\text { Events }\end{array}$ & Total & Weight & $\begin{array}{l}\text { Odds Ratio } \\
\text { M-H, Random, } 95 \% \mathrm{Cl}\end{array}$ & & $\begin{array}{l}\text { Odds Ratio } \\
\text { M-H, Random, } 95 \% \mathrm{Cl}\end{array}$ & \\
\hline Gleason 2018 & 50 & 202 & 47 & 202 & $57.4 \%$ & $1.08[0.69,1.71]$ & & & \\
\hline Petronio 2012 & 37 & 141 & 37 & 141 & $42.6 \%$ & $1.00[0.59,1.70]$ & & & \\
\hline Total $(95 \% \mathrm{Cl})$ & & 343 & & 343 & $100.0 \%$ & $1.05[0.74,1.48]$ & & & \\
\hline Total events & 87 & & 84 & & & & & & \\
\hline \multicolumn{6}{|c|}{$\begin{array}{l}\text { Heterogeneity: } \mathrm{Tau}^{2}=0.00 ; \mathrm{Chi}^{2}=0.05, \mathrm{df}=1(P=0.82) ; \mathrm{I}^{2}=0 \% \\
\text { Test for overall effect: } Z=0.26(P=0.79)\end{array}$} & & 0.01 & $0.1{ }^{1}{ }^{1} \quad 10$ & 100 \\
\hline
\end{tabular}

Acute kidney injury

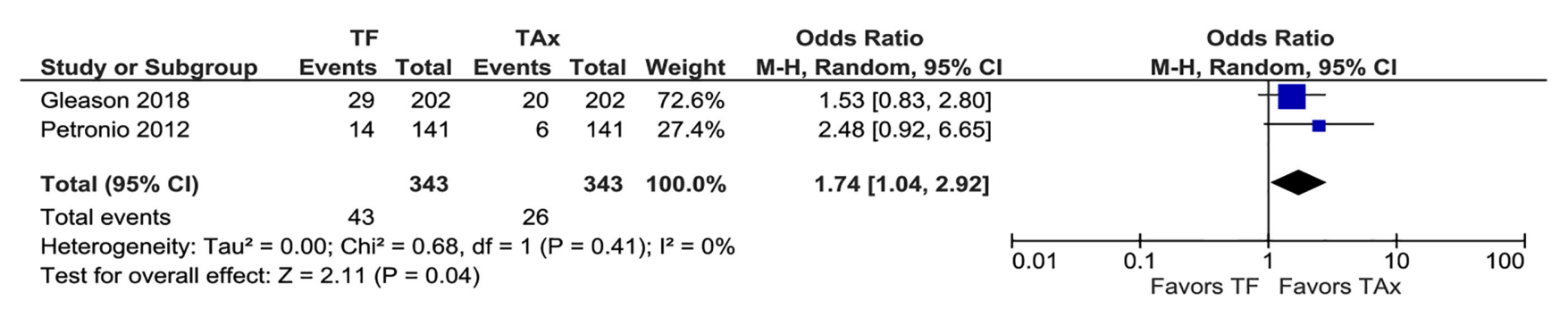

Figure 3 Forest plots for the comparison of outcomes of patients undergoing transaxillary and transfemoral TAVR in the two propensitymatched studies. TAx, transaxillary; TF, transfemoral.

described for TF-TAVR (21). We speculate that the numerically but not statistically superior 30-day mortality of TAx-TAVR compared to TF-TAVR, as seen in Figure 2, could be due to publication bias. A subgroup analysis of two propensity-matched studies also supports this notion with the differences between the two groups even less pronounced (Figure 3). The non-significant trend toward lower 1-year mortality favoring the TF group might be related to the higher rate of comorbidities observed in the TAx group, although the discrepancy in the risk profiles did not appear to affect the perioperative outcomes adversely. The survival benefits were also not revealed by the subgroup analysis of the propensity-matched studies (Figure 3). As aforementioned, the de facto choice for TAVR has conventionally been TF access, whereas TAxTAVR is considered when patients are not amenable to TFTAVR. Taken together, these data suggest the survival of TAx-TAVR can be equivalent to TF-TAVR, especially in a risk-adjusted patient population. However, with concerns over increased risk of vascular complications and sometimes anatomical restraints, the axillary artery is often considered only when femoral access is not feasible.

With the advances in the TAVR devices and techniques, an alternative access is currently performed in only a small 
subset of TAVR procedures $(3,7)$. The patients included in our meta-analysis were primarily high-risk cohorts, and the device studied was restricted to the previous-generation CoreValve. While the indication of TAVR is expanding rapidly to include low- or intermediate-risk patients, data on the outcomes of alternative access in these patient populations is lacking $(33,34)$. As TAVR outcomes relate to patients' characteristics and device features, such as profile and maneuverability, the applicability of TAx-TAVR potentially as the alternative access of choice for lower-risk patients and newer-generation devices deserves a careful examination.

\section{Study limitations}

Evidence remains limited in the literature concerning the outcomes of TAx-TAVR vs. TF-TAVR. As of this time, there is no randomized controlled trial on this subject. The major limitation of our study stems from the small number of studies qualified for the meta-analysis. The implication of our meta-analysis is also limited by the variations among the studies included in this analysis. There is inherent heterogeneity between different studies in terms of study design, description of baseline data, and outcome measures. While two of the studies included in this meta-analysis were propensity-matched with similar patient demographics, the other studies had major differences including patient baseline characteristics between the two groups.

\section{Conclusions}

TAx-TAVR is associated with overall outcomes comparable to TF-TAVR, despite a higher incidence of major comorbidities associated with the TAx-TAVR patient population. Although randomized controlled trials are required to establish its safety and efficacy, TAx-TAVR appears to be an excellent option for alternative access when femoral access is not available. While the current evidence is restricted to TAx-TAVR in high-risk patients, the outcomes of TAx-TAVR in the low- or intermediate-risk patient population remain to be studied. Additionally, our finding of a low AKI rate after TAx-TAVR warrants further investigation.

\section{Acknowledgments}

None.

\section{Footnote}

Conflicts of Interest: The authors have no conflicts of interest to declare.

Ethical Statement: The authors are accountable for all aspects of the work in ensuring that questions related to the accuracy or integrity of any part of the work are appropriately investigated and resolved.

\section{References}

1. Bavaria JE, Tommaso CL, Brindis RG, et al. 2018 AATS/ ACC/SCAI/STS Expert Consensus Systems of Care Document: Operator and institutional recommendations and requirements for transcatheter aortic valve replacement: A joint report of the American Association for Thoracic Surgery, American College of Cardiology, Society for Cardiovascular Angiography and Interventions, and Society of Thoracic Surgeons. Ann Thorac Surg 2019;107:650-84.

2. Baumgartner H, Falk V, Bax JJ, et al. 2017 ESC/EACTS Guidelines for the management of valvular heart disease. Eur Heart J 2017;38:2739-91.

3. Madigan M, Atoui R. Non-transfemoral access sites for transcatheter aortic valve replacement. J Thorac Dis 2018;10:4505-15.

4. Gleason TG, Schindler JT, Hagberg RC, et al. Subclavian/ axillary access for self-expanding transcatheter aortic valve replacement renders equivalent outcomes as transfemoral. Ann Thorac Surg 2018;105:477-83.

5. Muensterer A, Mazzitelli D, Ruge H, et al. Safety and efficacy of the subclavian access route for TAVI in cases of missing transfemoral access. Clin Res Cardiol 2013;102:627-36.

6. Petronio AS, De Carlo M, Bedogni F, et al. 2-year results of CoreValve implantation through the subclavian access: a propensity-matched comparison with the femoral access. J Am Coll Cardiol 2012;60:502-7.

7. Lanz J, Greenbaum A, Pilgrim T, et al. Current state of alternative access for transcatheter aortic valve implantation. EuroIntervention 2018;14:AB40-AB52.

8. Fröhlich GM, Baxter PD, Malkin CJ, et al. Comparative survival after transapical, direct aortic, and subclavian transcatheter aortic valve implantation (data from the UK TAVI registry). Am J Cardiol 2015;116:1555-9.

9. Blackman DJ, Baxter PD, Gale CP, et al. Do outcomes from transcatheter aortic valve implantation vary according 
to access route and valve type? The UK TAVI Registry. J Interv Cardiol 2014;27:86-95.

10. Ciuca C, Tarantini G, Latib A, et al. Trans-subclavian versus transapical access for transcatheter aortic valve implantation: A multicenter study. Catheter Cardiovasc Interv 2016;87:332-8.

11. Alexander B, Angaramo G, Walz JM, et al. A Novel approach to managing trans-subclavian transcatheter aortic valve replacement with regional anesthesia. J Cardiothorac Vasc Anesth 2018;32:1391-3.

12. Abdel-Wahab M, Mehilli J, Frerker C, et al. Comparison of balloon-expandable vs self-expandable valves in patients undergoing transcatheter aortic valve replacement: the CHOICE randomized clinical trial. JAMA 2014;311:1503-14.

13. Amat-Santos IJ, Rojas P, Gutiérrez H, et al. Transubclavian approach: A competitive access for transcatheter aortic valve implantation as compared to transfemoral. Catheter Cardiovasc Interv 2018;92:935-44.

14. Garcia DC, Benjo A, Cardoso RN, et al. Device stratified comparison among transfemoral, transapical and transubclavian access for transcatheter aortic valve replacement (TAVR): a meta-analysis. Int J Cardiol 2014;172:e318-21.

15. Phan K, Tian DH, Cao C, et al. Systematic review and meta-analysis: techniques and a guide for the academic surgeon. Ann Cardiothorac Surg 2015;4:112-22.

16. Moher D, Liberati A, Tetzlaff J, et al. Preferred reporting items for systematic reviews and meta-analyses: the PRISMA statement. Int J Surg 2010;8:336-41.

17. Wang N, Tsai YC, Niles N, et al. Transcatheter aortic valve implantation (TAVI) versus sutureless aortic valve replacement (SUAVR) for aortic stenosis: a systematic review and meta-analysis of matched studies. J Thorac Dis 2016;8:3283-93.

18. Eltchaninoff H, Prat A, Gilard M, et al; FRANCE Registry Investigators. Transcatheter aortic valve implantation: early results of the FRANCE (FRench Aortic National CoreValve and Edwards) registry. Eur Heart J 2011;32:191-7.

19. Siontis GC, Juni P, Pilgrim T, et al. Predictors of permanent pacemaker implantation in patients with severe aortic stenosis undergoing TAVR: a meta-analysis. J Am Coll Cardiol 2014;64:129-40.

20. van Rosendael PJ, Delgado V, Bax JJ. Pacemaker implantation rate after transcatheter aortic valve implantation with early and new-generation devices: a systematic review. Eur Heart J. 2018;39:2003-13.

21. van der Wulp K, Verkroost MWA, van Wely MH, et al. Feasibility and outcomes of transcatheter aortic valve implantation using the left axillary artery as primary access site. Ann Thorac Surg 2019;107:546-52.

22. Godino C, Maisano F, Montorfano M, et al. Outcomes after transcatheter aortic valve implantation with both Edwards-SAPIEN and CoreValve devices in a single center: the Milan experience. JACC Cardiovasc Interv 2010;3:1110-21.

23. Vavuranakis M, Vrachatis DA, Filis K, et al. Transcatheter aortic-valve implantation by the subclavian approach complicated with vessel dissection and transient left-arm paralysis. Eur J Cardiothorac Surg 2011;39:127-9.

24. Bruschi G, De Marco F, Fratto P, et al. Alternative approaches for trans-catheter self-expanding aortic bioprosthetic valves implantation: single-center experience. Eur J Cardiothorac Surg 2011;39:e151-8.

25. Reardon MJ, Van Mieghem NM, Popma JJ, et al. Surgical or transcatheter aortic-valve replacement in intermediaterisk patients. N Engl J Med 2017;376:1321-31.

26. Gilard M, Eltchaninoff H, Iung B, et al. Registry of transcatheter aortic-valve implantation in high-risk patients. N Engl J Med 2012;366:1705-15.

27. Linke A, Wenaweser P, Gerckens U, et al. Treatment of aortic stenosis with a self-expanding transcatheter valve: the international multi-center ADVANCE study. Eur Heart J 2014;35:2672-84.

28. Tayal R, Hawatmeh A, Thawabi M, et al. Percutaneous transaxillary transcatheter aortic valve replacement. J Invasive Cardiol 2017;29:E72-3.

29. Deuschl F, Schofer N, Seiffert M, et al. Direct percutaneous transaxillary implantation of a novel selfexpandable transcatheter heart valve for aortic stenosis. Catheter Cardiovasc Interv 2017;90:1167-74.

30. Schäfer U, Deuschl F, Schofer N, et al. Safety and efficacy of the percutaneous transaxillary access for transcatheter aortic valve implantation using various transcatheter heart valves in 100 consecutive patients. Int J Cardiol 2017;232:247-54.

31. Laflamme M, Mazine A, Demers P, et al. Transcatheter aortic valve implantation by the left axillary approach: a single-center experience. Ann Thorac Surg 2014;97:1549-54.

32. Taramasso M, Maisano F, Cioni M, et al. Transapical and trans-axillary percutaneous aortic valve 
implantation as alternatives to the femoral route: short- and middle-term results. Eur J Cardiothorac Surg 2011;40:49-55.

33. Mack MJ, Leon MB, Thourani VH, et al. Transcatheter aortic-valve replacement with a balloon-expandable valve in low-risk patients. N Engl J Med 2019;380:1695-705.

34. Popma JJ, Deeb GM, Yakubov SJ, et al. Transcatheter aortic-valve replacement with a self-expanding valve in low-risk patients. N Engl J Med 2019;380:1706-15.

Cite this article as: Zhan $\mathrm{Y}$, Saadat $\mathrm{S}$, Soin A, Kawabori M, Chen FY. A meta-analysis comparing transaxillary and transfemoral transcatheter aortic valve replacement. J Thorac Dis 2019;11(12):5140-5151. doi: 10.21037/jtd.2019.12.07 